\title{
Cell localisation of gadolinium-based nanoparticles and related radiosensitising efficacy in glioblastoma cells
}

Lenka Štefančíková ${ }^{1}$, Erika Porcel ${ }^{1}$, Pierre Eustache' ${ }^{1}$, Sha Li ${ }^{1}$, Daniela Salado ${ }^{1}$, Sergio Marco ${ }^{2,3}$, Jean-Luc Guerquin-Kern ${ }^{2,3}$, Matthieu Réfrégiers ${ }^{4}$, Olivier Tillement ${ }^{5}$, François Lux ${ }^{5}$ and Sandrine Lacombe ${ }^{1 *}$

\author{
* Correspondence: \\ sandrine.lacombe@u-psud.fr \\ ${ }^{1}$ Institut des Sciences Moléculaires \\ d'Orsay (UMR 8214) Bât 351, \\ Université Paris Sud, CNRS, 91405 \\ Orsay Cedex, France \\ Full list of author information is \\ available at the end of the article
}

\begin{abstract}
Recently, the addition of nanoparticles (NPs) has been proposed as a new strategy to enhance the effect of radiotherapy particularly in the treatment of aggressive tumors such as glioblastoma. The physical processes involved in radiosensitisation by nanoparticles have been well studied although further understanding of its biological impact is still lacking, and this includes the localisation of these NPs in the target cells. Most studies were performed with NPs tagged with fluorescent markers. However, the presence of these markers can influence the NPs uptake and localisation. In this study, a set of methods was used to unambiguously and fully characterise the uptake of label-free NPs, their co-localisation with cell organelles, and their radiosensitising efficacy. This set was applied to the case of gadolinium-based nanoparticles (GdBN) used to amplify the radiation killing of U87 glioblastoma cells extracted from highly aggressive human tumor. For the first time, Synchrotron Radiation Deep UV (SR-DUV) microscopy is proposed as a new tool to track label-free GdBN. It confirmed the localisation of the NPs in the cytoplasm of U87 cells and the absence of NPs in the nucleus. In a second step, Transmission Electron Microscopy (TEM) demonstrated that GdBN penetrate cells by endocytosis. Third, using confocal microscopy it was found that GdBN co-localise with lysosomes but not with mitochondria. Finally, clonogenic assay measurements proved that the presence of NPs in the lysosomes induces a neat amplification of the killing of glioblastoma cells irradiated by gamma rays. The set of combined experimental protocols-TEM, SR-DUV and confocal microscopy_-demonstrates a new standard method to study the localisation of label-free NPs together with their radiosensitising properties. This will further the understanding of NP-induced radiosentisation and contribute to the development of nanoagents for radiotherapy.
\end{abstract}

Keywords: Radiosensitisation; Nanomedicine; Tumor targeting; Theranostic; Gadolinium- based nanoparticles; Localisation; Deep-UV synchrotron microscopy; Glioblastoma

\section{Springer}

(C) 2014 Stefancikova et al.; licensee Springer. This is an Open Access article distributed under the terms of the Creative Commons Attribution License (http://creativecommons.org/licenses/by/4.0), which permits unrestricted use, distribution, and reproduction in any medium, provided the original work is properly credited. 


\section{Background}

Glioblastoma multiforme (GBM) is a highly aggressive tumor with median survival time of patients of 12 months [1]. Hence, the treatment of this type of cancer remains a challenge. Recently, high-Z atoms containing nanoparticles (NPs) have been proposed as potential nanodrugs to improve the effects of radiation-based therapies [2-5]. Among metal-based NPs, gold NPs were widely used for diagnostic as contrast agents and in therapy [6-10]. Gold NPs were found to enhance the effects of mid- and high-energy $\mathrm{X}$-rays $[2,4-6,11]$. In parallel, it was shown that NPs composed of other metals such as platinum are able to enhance lethal damage to biomolecules when gamma rays or fast medical ions $\left(\mathrm{He}^{2+}\right.$ and $\left.\mathrm{C}^{6+}\right)$ are used as ionising radiations [12].

Gadolinium-based nanoparticles (GdBN) act as multimodal agents; it offers a strong advantage to improve not only the therapeutic index of the treatment but also the diagnosis of tumor by MRI (theranostic) [13-16]. Importantly, in vivo experiments demonstrated that these NPs are rapidly eliminated by the kidneys and show no evidence of toxicity (no perturbation of the complement system, no impairment of the renal function) [17-20]. It was found that GdBN amplify significantly radiation-induced killing of U87 glioblastoma cells when combined with high-energy X-rays and gamma rays [21,22], or with fast ions [23].

The amplification effects induced by high-Z NPs are explained in terms of early stage processes that take place in the cells. Briefly, when activated by the incident radiation, NPs are responsible for the emission of electron bursts and the production of radical clusters (reactive oxygen species). Consecutively highly lethal nano-sized damages are induced in cell constituents as due to the interaction of the highly reactive clusters with biomolecules $[24,25]$.

So far it was shown that platinum compounds (NPs or salts), gold nanoparticles and GdBN amplify cell killing even though they do not enter cell nuclei [23,26-30]. Experiments focused on the NPs localisation were conducted using Transmission Electron Microscopy (TEM) and/or confocal microscopy as standard methods. TEM allows high resolution $(10 \mathrm{~nm})$ observation of cell organelles such as liposomes and mitochondria. The limitation of this technique, however, stems from the difficult sample preparation, which may change the morphology of the cells [31]. In confocal microscopy, the experiments are performed with living cells, thus measurements of the uptake dynamic and co-localisation with cell organelles (lysosomes, mitochondria) can be performed. The limitation of confocal microscopy stems from the necessity to tag the NPs with fluorescent dyes such as rhodamine, cyanine, or BoDIPYs [32]. These markers may influence the internalisation and the localisation of the NPs in the cells. Moreover, if the dyes separate from the NPs, the fluorescent images may lead to false interpretation [33-35].

The main goal of the present work is to determine the localisation and related radiosensitising properties of label-free GdBN in human glioblastoma cells (U87) in different conditions of incubation. The localisation of label-free NPs was performed with a novel microscopy tool, the Synchrotron-Radiation Deep UV (SR-DUV) microscopy. The excitation window of the synchrotron source goes down to $190 \mathrm{~nm}$. The instrument is thus able to excite and detect the natural fluorescence of nanoparticles that absorb in the Deep-UV spectral range (below $350 \mathrm{~nm}$ ). This microscope has been used to follow the intake of antibiotics in bacteria [36]. Here, we show for the first time that the technique can be applied in the observation of label-free NP uptake in cells. As a complementary 
tool, TEM was used to characterise the uptake mechanism of GdBN in U87 cells. Additional measurements using confocal microscopy were used to follow the dynamics of NPs in living cells and also to co-localise the GdBN with lysosomes and mitochondria, two important organelles in cell metabolism. The effect of GdBN on the radiation induced cell killing of U87 glioblastoma cells irradiated by gamma rays $1.25 \mathrm{MeV}$ was evaluated using clonogenic assay [22].

\section{Methods}

Gadolinium-based nanoparticles ( $G d B N$ ) were synthesised by the group of O. Tillement (LPCML, Lyon, France) [13]. Briefly, the GdBN consist of a polysiloxane core surrounded by gadolinium chelates covalently grafted on the inorganic matrix. The synthesis procedure and the characteristics of these nanoparticles are detailed elsewhere [22,37]. Their size is $3 \pm 1 \mathrm{~nm}$ in diameter and their mass is about $8.5 \pm 1.0 \mathrm{kDa}$ [22,37]. After freeze-drying, the GdBN can be stored at $4{ }^{\circ} \mathrm{C}$ for months. For SR-DUV microscopy and TEM measurements, label-free GdBN were used. For the experiments of confocal microscopy, the organic fluorophore cyanine 5.5 was covalently grafted onto $\operatorname{GdBN}[15,22,38]$. The concentration of GdBN in the medium is expressed in the concentration of Gd, i. e., $1 \mathrm{mM}$ of Gd is approximately equal to $0.1 \mathrm{mM}$ of nanoparticles. In this study we used Gd concentrations ranging from 0.5 to $2 \mathrm{mM}$, which are not toxic for U87 cells [30].

\section{Cell culture}

Human glioblastoma U87 cells were cultivated in Dulbecco's Modified Eagle Medium (DMEM) (Life Technologies) supplemented with 10\% heat-inactivated foetal bovine serum (PAA), $100 \mathrm{U} / \mathrm{ml}$ penicillin (PAA), $100 \mu \mathrm{g} / \mathrm{ml}$ streptomycin (PAA) and $1 \%$ Non Essential Amino Acids (Life Technologies).

\section{SR-DUV fluorescence microscopy}

Cells were plated on quartz slides (ESCO OPTICS Inc) and maintained in $5 \% \mathrm{CO}_{2}$ incubator at $37^{\circ} \mathrm{C}$. Medium containing GdBN at $0.5 \mathrm{mM}$ or $2 \mathrm{mM}$ concentration was added to the cells during 5 min or 1 hour. After the incubation, cells were rinsed twice with PBS 1X (5 min at room temperature), fixed with 4\% paraformaldehyde in PBS 1X (20 min at room temperature), rinsed with distilled water, dried and stored at $4{ }^{\circ} \mathrm{C}$. The SR-DUV experiments were performed at the DISCO beamline of Synchrotron SOLEIL (Saint-Aubin, France).

The fluorescence images were recorded at $\lambda_{\text {exc }}=340 \mathrm{~nm}$. The acquisition time of one image was $30 \mathrm{~s}$. Images of minimum three cells were recorded for each condition including the control. Sixty images with a vertical z-stack of $0.25 \mu \mathrm{m}$ were acquired to obtain a 3D record of the GdBN localisation in the cells. The Tikhonov-Miller deconvolution was applied to correct the distortion of the images. The images were finally analysed with ImageJ software (Rasband, W.S., ImageJ, U. S. National Institutes of Health, Bethesda, Maryland, USA, http://imagej.nih.gov/ij/, 1997-2011). The total fluorescence intensity of each cell was determined using ImageJ (integrated density, ID). The background was obtained by measuring the fluorescence intensity of regions out of the cells. The corrected total cell fluorescence (CTCF) was then determined by subtracting the background from the integrated density (CTCF = ID - background). 


\section{Transmission electron microscopy (TEM)}

It was performed on the microscopy platform IBiSA at the Institut Curie, Orsay, France. U87 cells were plated on microscopic glass slides. The samples were incubated with $1 \mathrm{mM}$ GdBN during 1 hour. The slides were then rinsed with PBS $1 \mathrm{X}$ and fixed with a mixture of $2.5 \%$ glutaraldehyde and $4 \%$ paraformaldehyde diluted in PBS $1 \mathrm{X}$. After rinsing with PBS $1 \mathrm{X}$, the cells were dehydrated using ethanol in gradient concentrations and embedded step by step in Epon resin. After resin polymerisation, the samples were cut using an ultramicrotome in $100 \mathrm{~nm}$-thick slices. The ultrathin sections were deposited on carbon-formvar copper grids (Agar scientific) and observed under Z-loos mode (10 eV window) in a JEOL 2200FS electron microscope operated at $200 \mathrm{kV}$. Measurements were performed for close to 20 U87 cells of 4 different slices. Additional Electron Energy Loss Spectroscopy (EELS) measurements were performed using an omega-filter.

\section{Confocal microscopy studies}

The experiments were performed with a LEICA SP5 confocal system located at the Centre de Photonique Bio-Medical (CPBM), University Paris Sud, Orsay, France. The samples were thermostatically controlled and regulated in $\mathrm{CO}_{2}$. U87 cells were grown in 8-well LabTek chambers (Nalge Nunc International). For simple localisation studies, the cells were incubated with 0.6 or $1 \mathrm{mM}$ of $\mathrm{GdBN}$ functionalised with cyanine 5.5 used as a fluorescent marker (GdBN-Cy5.5) during different incubation times (1 hour, 6 hours and 12 hours). After incubation the cells were rinsed three times with PBS 1X and Hank's Balanced Salt Solution (HBSS) was added. Cyanine 5.5 was excited at $633 \mathrm{~nm}$ and the fluorescence emission was detected in the $650-750 \mathrm{~nm}$ range. The localisation was studied in more than 100 cells.

For co-localisation studies, U87 cells were incubated with Lysotracker-green (Invitrogen) (75 nM) or Mitotracker-green (Invitrogen) (200 nM) dissolved in HBSS and mixed with DMEM for 45 minutes. The trackers were washed out with PBS $1 \mathrm{X}$ before incubation during 1 hour with $1 \mathrm{mM}$ of GdBN-Cy5.5. After incubation the cells were rinsed three times with PBS $1 \mathrm{X}$ and Hank's Balanced Salt Solution (HBSS) was added. Cyanine 5.5 was excited at $633 \mathrm{~nm}$ and the fluorescence emission was detected in the $650-750 \mathrm{~nm}$ range. The lysotracker and mitotracker were excited at $488 \mathrm{~nm}$ and the fluorescence emission was detected in the 505-600 nm range. Images were recorded at three different depths ( $\mathrm{z}$ axispositions). The co-localisation of GdBN with lysosomes and mitochondria was evaluated using the ImageJ software and the JACoP statistical plug-in (Just Another Co-localisation Plugin) (http://rsb.info.nih.gov/ij/plugins/track/jacop.html). The co-localisation coefficients were calculated for more than 30 cells.

\section{Gamma radiation experiments}

$1.5 \times 10^{5}$ exponentially growing U87 cells were plated in Petri dishes (Falcon 3002) 12 hours before irradiation. Cells were maintained in a $5 \% \mathrm{CO}_{2}$ incubator at $37^{\circ} \mathrm{C}$. GdBN were added to the cell medium 6 hours before irradiation at a gadolinium concentration of $0.5 \mathrm{mM}$. At this concentration, the nanoparticles are not toxic $[19,20]$. The U87 cells were irradiated at room temperature under atmospheric conditions. The irradiations were performed with a cobalt source $\left({ }^{60} \mathrm{Co}\right)$ at CEA (Fontenay aux Roses, France) at a mean energy of $1.25 \mathrm{MeV}$, a linear energy transfer (LET) of $0.2 \mathrm{keV} / \mu \mathrm{m}$ 
and a dose rate of $1 \mathrm{~Gy} / \mathrm{min}$. The combined effect of radiation and nanoparticles on cells was quantified by clonogenic assay. After irradiation, the cells were fixed by trypsin and plated into $100 \mathrm{~mm}$ Petri dishes (Falcon 3002) at a density of 100 surviving cells per dish. The plating efficiency was found close to $20 \%$. After 14 days, the colonies were treated with $50 \%$ methanol and stained by $0.5 \%$ methylene blue. The colonies were counted to determine the survival fractions.

\section{Results and discussion}

\section{Localisation of label-free GdBN in U87 cells with SR-DUV microscopy}

In a first step, the spectroscopic properties of GdBN $(1 \mathrm{mM})$ were determined by performing the fluorescence excitation spectroscopy and the fluorescence emission spectroscopy of NPs diluted in ultra-pure water (Figure 1). GdBN exhibited the maximum fluorescence emission at $\boldsymbol{\lambda}_{\mathrm{em}}=440 \mathrm{~nm}$ and the maximum excitation at $\boldsymbol{\lambda}_{\mathrm{exc}}=360 \mathrm{~nm}$.

In cells, an autofluorescence is generated by natural fluorophores, mainly $\mathrm{NADH}$, tyrosine, and tryptophan [39]. To obtain the best signal of the NPs over the autofluorescence, the excitation wavelength $\lambda_{\text {exc }}=340 \mathrm{~nm}$ was chosen for all the microscopy experiments.

In a second step, the fluorescence microscopy of GdBN in U87 cells was recorded. The experiments were performed with cells incubated with GdBN at two concentrations $(0.5$ and $2 \mathrm{mM})$ during 5 minutes or 1 hour. The result obtained for the GdBN concentration of $2 \mathrm{mM}$ and the incubation time of $5 \mathrm{~min}$ is presented in Figure 2. Light transmission micrograph was used to display the shape of the cells (Figure 2A). The nucleus of the cell was clearly distinguished as pointed in the figure. This image shows that the cell did not suffer from the sample preparation. Figure $2 \mathrm{~B}$ corresponds to the SR-DUV fluorescence image. It shows that GdBN were present. The merge of Figures $2 \mathrm{~A}$ and $\mathrm{B}$ (Figure $2 \mathrm{C}$ ) is used to show the localisation of GdBN in cells. We clearly observe that GdBN free of fluorescent dye enter the cells and remain located in the cytoplasm exclusively.

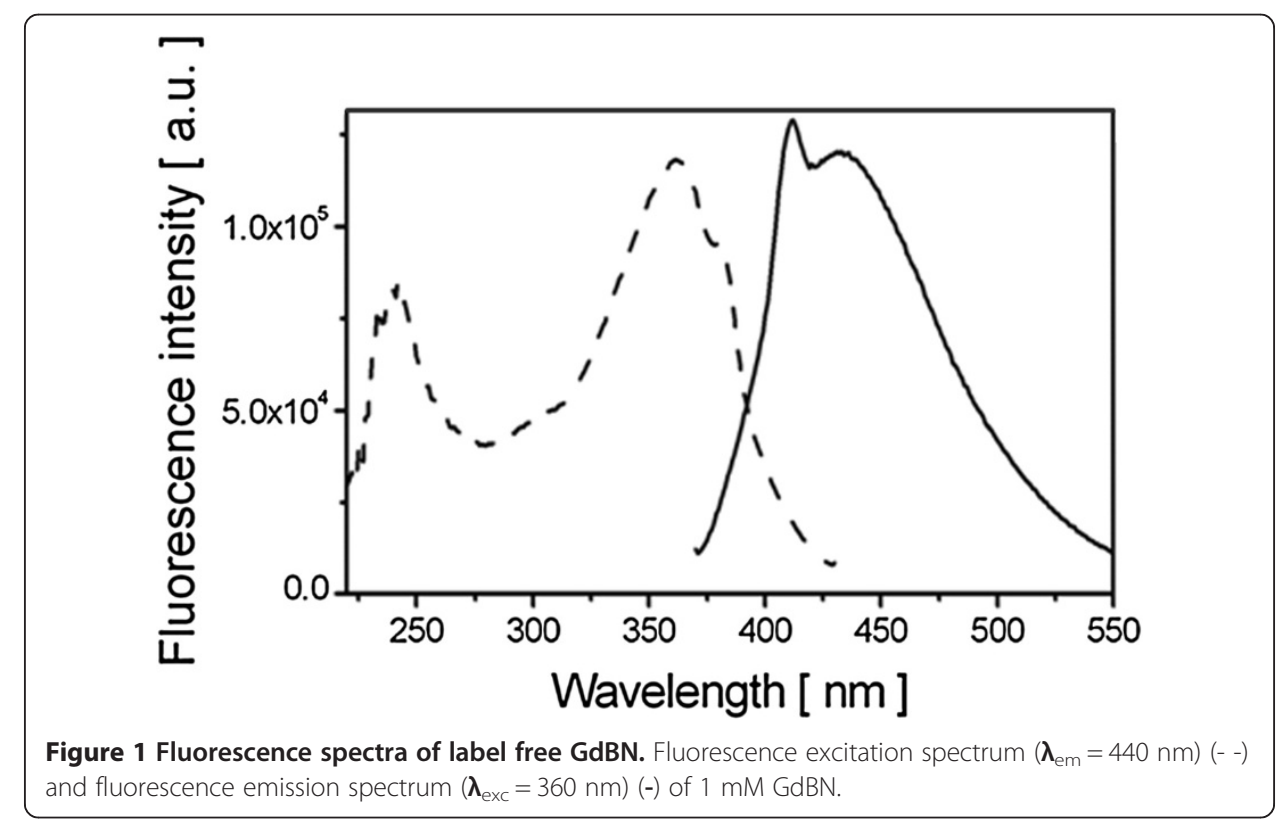




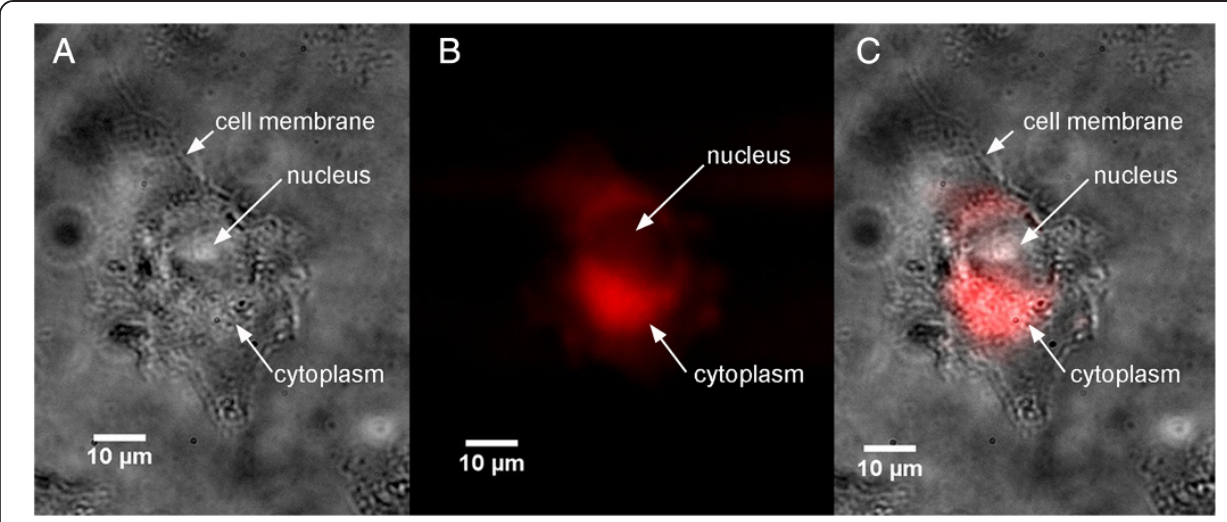

Figure 2 Localisation of GdBNs in U87 cells visualised by SR-DUV microscopy. (A) Light transmission image of U87 cell, (B) fluorescence image of label free GdBN (red), (C) merge of transmission and fluorescence images (GdBN in red).

In order to investigate the influence of the GdBN concentration and incubation time on NPs uptake, we calculated the corrected total cell fluorescence (CTCF) values for cells free of GdBN (controls) and cells loaded with two concentrations (0.5 and $2 \mathrm{mM}$ ) for the two incubation times ( $5 \mathrm{~min}$ and 1 hour). The CTCF values are summarised in Table 1.

The present analysis shows that there was a high variability of fluorescence intensity between the different cells. This indicates that the uptake was not homogeneous in every cell. Interestingly, GdBN are already efficiently internalised in the cells after 5 minutes. However the concentration of GdBN in the medium $(0.5 \mathrm{mM}$ and $2 \mathrm{mM})$ did not impact the quantity of GdBN in the cells. This last result seems different from the measurements of Rima and coworkers who observed a linear increase of the Gd concentration in U87 and SQ20B cells whilst increasing the GdBN concentration in the cultivation medium [30]. However their study was performed using the Inductively Coupled Plasma (ICP) technique, which consists of the quantification of internalised Gd averaged over millions of cells. Contrary to this macroscopic technique, SR-DUV microscopy gives rise to the internalisation of GdBN in each cell. This allows the observation of differences between cells as observed in the present study. This type of cell-to-cell heterogeneity was recently observed in the case of magnetic NPs [40]. The heterogeneity in the capacity of cells to internalise NPs could influence their efficacy of amplifying radiation effects. It is thus a great challenge to study and quantify the heterogeneity in the uptake of label free-NPs which has never been done so far. This possibility offered by SR-DUV microscopy is still in the process of development.

Table 1 CTCF values measured in U87 cells with and without NPs

\begin{tabular}{ccccccc}
\hline GdBN concentration $[\mathrm{mM}]$ & $\begin{array}{c}\text { GdBN } \\
\text { incubation time }\end{array}$ & Mean CTCF & $\begin{array}{c}\text { CTCF } \\
\text { cell 1 }\end{array}$ & $\begin{array}{c}\text { CTCF } \\
\text { cell 2 }\end{array}$ & $\begin{array}{c}\text { CTCF } \\
\text { cell 3 }\end{array}$ & $\begin{array}{c}\text { CTCF } \\
\text { cell 4 }\end{array}$ \\
\hline 2 & 5 minutes & $\mathbf{3 . 8 8} \mathbf{1 0}^{\mathbf{7}}$ & $7.5810^{7}$ & $1.6510^{7}$ & $4.1510^{7}$ & $2.1210^{7}$ \\
\hline 2 & 1 hour & $\mathbf{2 . 8 4} \mathbf{1 0}^{\mathbf{7}}$ & $2.6810^{7}$ & $1.3310^{7}$ & $2.1910^{7}$ & $5.1610^{7}$ \\
\hline 0.5 & 1 hour & $\mathbf{2 . 8 6} \mathbf{1 0}^{\mathbf{7}}$ & $4.7710^{7}$ & $1.1310^{7}$ & $2.6810^{7}$ & \\
\hline 0 (control) & & $\mathbf{1 . 7 0 1 0 ^ { \mathbf { 7 } }}$ & $1.3610^{7}$ & $2.1410^{7}$ & $1.6010^{7}$ & \\
\hline
\end{tabular}




\section{Uptake mechanism of label-free GdBN in U87 cells investigated by TEM}

TEM measurements have been performed to observe the internalisation of NPs with a better resolution $(10 \mathrm{~nm})$ and determine the mechanism(s) of NPs uptake.

Images have been recorded for more than 20 samples (see Experimental section). An example of TEM image is presented in Figure 3. For all the samples we observe electron dense regions close to the cell membrane (Figure 3A and $3 \mathrm{~B}$ ) and in the cytoplasm (Figure $3 \mathrm{C}$ and $3 \mathrm{D}$ ). The magnification image (Figure $3 \mathrm{~B}$ ) shows that these regions are composed of small electron dense objects. These are attributed to nanoparticles clusters. No electron dense regions were found in the cell nucleus (image not shown here).

To confirm the composition of these dense granules, EELS spectra of these regions have been performed close to the membrane and in the cytoplasm (Figure 3E and 3F). The peaks M4 and M5 are characteristic of gadolinium. Finally, these TEM and EELS
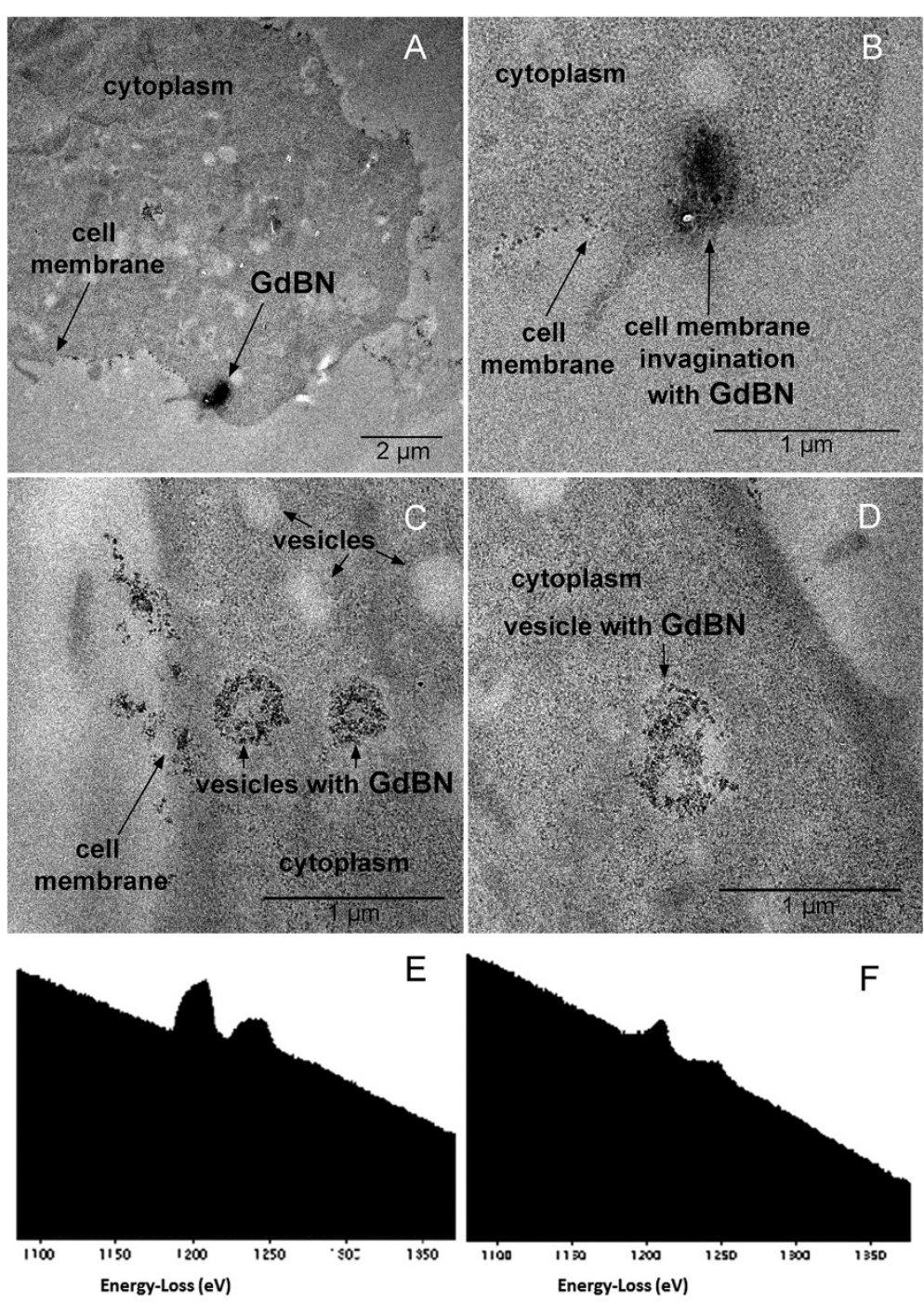

Figure 3 TEM images of U87 cells after incubation with $1 \mathrm{mM} \mathrm{GdBN}$ for 1 hour. (A) Image of a cell with electron dense regions located close to the membrane. (B) Zoom of the electron dense region shown in $\mathbf{A}$. (C and D) Images of cells with electron dense regions located in the cytoplasm. (E) EELS spectrum of a electron dense region evidenced in (A). (F) EELS spectrum of a electron dense region evidenced in (C). 
measurements confirm that GdBN entered U87 cells and located in the cytoplasm but do not penetrate the cell nuclei.

Interestingly NPs clusters appear in low electron density regions. These regions are assigned to vesicles. The average diameter of these vesicles is $400-600 \mathrm{~nm}$, which corresponds to endosomes and lysosomes [41]. In the images $3 \mathrm{~A}$ and $3 \mathrm{~B}$ we also observe the presence of membrane invaginations. These observations strongly suggest that $\mathrm{GdBN}$ were internalised by endocytosis. Indeed, this uptake mechanism is characterised by the induction of membrane invagination followed by trafficking from early endosomes to late endosomes and lysosomes as observed in the TEM images.

It is noteworthy to mention that GdBN have a size $(3 \mathrm{~nm})$ close to macromolecules such as proteins. These entities are generally transported to cells by pathways such as phagocytosis, macropinocytosis, clathrin-dependent endocytosis, caveolin-dependent endocytosis and clathrin/caveolinin dependent endocytosis [42,43]. These mechanisms differ by the size of the vesicles, the nature of the transported species and the need of specific receptors [44]. Rima and co-workers [30] observed that, in the case of SQ20B cell line, GdBN are internalised via macropinocytosis. This process is characterised by the formation of membrane lamellipodia ("arms") which pick up particle aggregates [30]. In the present study, the presence of membrane invaginations is more indicative of a pathway such as clathrin-mediated endocytosis. The uptake of GdBN by endocytosis has been proposed by other groups $[45,46]$. In the case of nanodiamonds internalised in A549 lung cancer cells, it was shown that different pathways such as macropinocytosis and clathrin-mediated endocytosis may participate in the NPs uptake [47]. Similarly, various endocytosis mechanisms were used to describe the uptake of sub-20 nm titanium dioxide nanoparticles in prostate PC-3 M cancer cells [48].

Finally, the present study shows that in the case of U87 glioblastoma cells, GdBN were internalised by endocytosis. It is not clear yet what are the parameters that give advantage to one or more uptake pathways and how important this step is in the impact of NPs on the radiation effects. Additional studies are needed to answer these questions.

\section{Influence of fluorescent labelling on NPs uptake and co-localisation with cell organelles performed by confocal microscopy}

The other objective of this work was to co-localise GdBN with lysosomes and mitochondria of U87 cells. For this purpose, fluorescent labelling of GdBN was needed because confocal microscopy is the standard method used to image cell organelles. We first investigated the influence of cyanine 5.5 on the NPs localisation to prevent artefacts due to the presence of fluorescent dyes in the co-localisation measurements.

\section{Influence of cyanine 5.5 on the GdBN localisation in U87 cells.}

A representative fluorescent image of U87 cells loaded with GdBN tagged with cyanine 5.5 (GdBN-Cy5.5) is presented in Figure 4. This image confirmed that the NPs sit exclusively in the cytoplasm even in the presence of cyanine at the surface. Similar results were obtained for different conditions of incubation (GdBN concentrations 


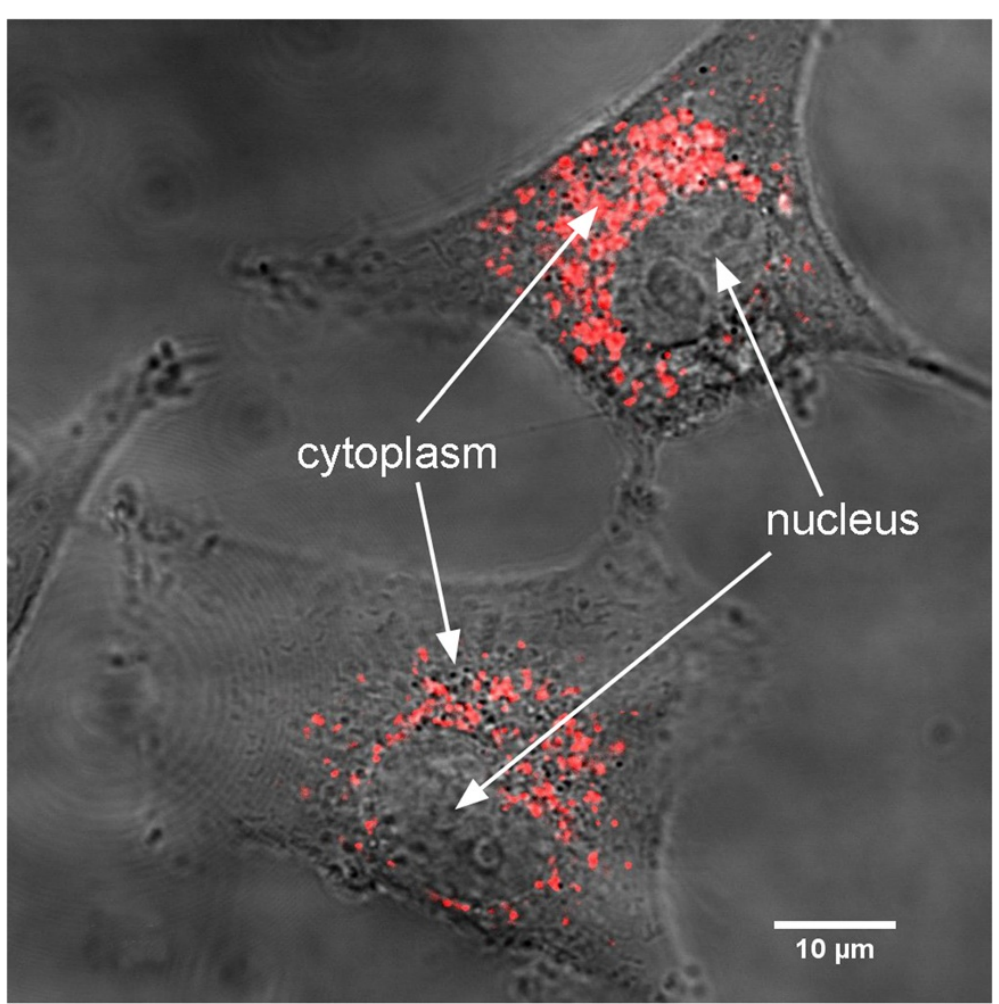

Figure 4 Merge image of the transmission and fluorescence images obtained by confocal microscopy of U87 cell loaded with GdBN-Cy5.5 (red) at a concentration of $0.6 \mathrm{mM}$ incubated for 12 hours.

and incubation times - see section Methods). Interestingly, NPs did not enter the nucleus but were located around the nuclei. This is in agreement with results obtained with GdBN localised in Chinese Hamster Ovary (CHO) cells [23] and U87 cells [22].

The GdBN clusters have a size distribution in the cell cytoplasm ranging from 400 to $900 \mathrm{~nm}$. This distribution was stable regardless of the NPs concentration $(0.6$ or $1 \mathrm{mM})$ and the incubation time ( 1 hour, 6 hours and 12 hours). When GdBN are conjugated with fluorescein- isothiocyanate (FITC) the clusters are larger and more irregular [22].

It is worth mentioning that GdBN remained localised in the cells for up to 37 hours (end of our observation), which indicates that the NPs had a long time of residence in U87 cells.

More importantly the localisation of GdBN tagged with cyanine 5.5 was similar to the localisation of label-free NPs as observed in TEM and SR-DUV microscopy. Thus, we have demonstrated without ambiguity that the addition of cyanine 5.5 did not influence the localisation of GdBN in U87 cells. In conclusion, confocal microscopy together with NPs labelling with cyanine can be used to perform additional measurements of co-localisation with cell organelles.

The novel methodological approach used here-combining TEM, SR-DUV and confocal microscopy-is proposed for other studies focused on the NPs localisation in cells. 


\section{Co-localisation of GdBN with cell organelles}

In a second step, we investigated the co-localisation of GdBN with lysosomes and mitochondria with confocal microscopy using cyanine as the fluorescent dye of the NPs.

Confocal microscopy images are presented in Figure 5. Figure 5A and 5D correspond to the fluorescence images of U87 cells loaded with GdBN-Cy5.5. Figure $5 \mathrm{~B}$ and $5 \mathrm{E}$ correspond to the fluorescence images of U87 cells incubated with Lysotracker-green or Mitotracker-green respectively. The merged images of GdBN-Cy5.5 with Lysotrackergreen (Figure 5C) and Mitotracker-green (Figure 5F) clearly demonstrate the colocalisation of GdBN-Cy5.5 with lysosomes but not with mitochondria.

A statistical analysis of the images was performed using ImageJ statistical plugin JACoP, a tool commonly used for co-localisation analysis. Briefly, this plugin gives access to the most important correlation coefficient-based tools (Pearson's coefficient, Manders' coefficient) and allows comparing various methods (Costes' approach, Van Steensel's approach, Li's approach) to evaluate the co-localisation [49]. The Pearson's correlation coefficient was used to quantify the correlation between the GdBN-Cy5.5 fluorescence and the lysosomes or mitochondria fluorescence. This correlation coefficient estimates the degree of overlap of the red and green spots of each dual-channel image [50]. This analysis was performed with the images recorded 20 hours after the incubation with GdBN-Cy5.5. The average Pearson's correlation coefficients obtained were 0.63 (SD 0.078) for the GdBN co-localisation with the lysosomes and 0.23 (SD 0.091 ) for the GdBN co-localisation with the mitochondria. Values in the 0.5 - 1 range indicate a co-localisation [51]. This analysis demonstrates that GdBN were co-localised with lysosomes. This was observed for 5 hours up to 37 hours after incubation. No colocalisation of GdBN with mitochondria was observed even after 37 hours.

Finally, the present experiment displayed lysosomes as being the preferential sites of GdBN in U87 cells.

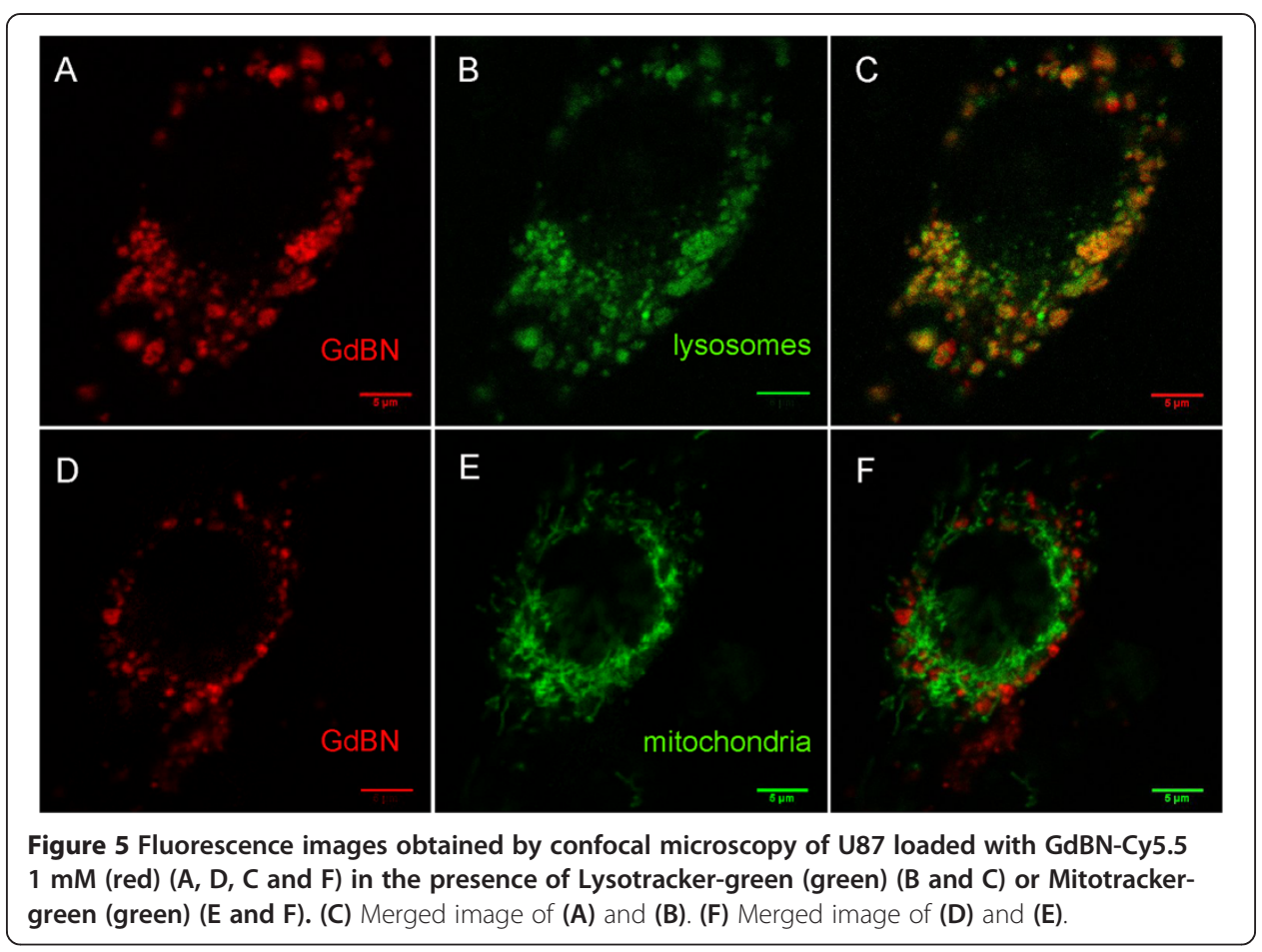


It should be noted that lysosomes are very acidic cellular vesicles that play a role in the transport and the degradation of intracellular and extracellular cargo. A perturbation of these entities (by radiation for instance) can induce lysosomal pathologies such as phospholipidosis, lysosomal overload, which result in the autophagy of the cells [52]. The presence of NPs of different sizes and composition in endosomes and lysosomes was shown by other groups [53-56].

\section{Influence of GdBN on gamma radiation effects in U87 cells}

The effect of GdBN on cells irradiated by gamma rays $(1.25 \mathrm{MeV})$ was investigated using the clonogenic assay as the analysis method of the radiation-induced cell killing (see Methods section). The survival curves of U87 cells free of nanoparticles (controls) and U87 cells loaded with GdBN $(0.5 \mathrm{mM})$ irradiated by gamma rays are presented in Figure 6.

The cell survival fractions decreased while the radiation dose increased. This decrease was clearly amplified in the presence of GdBN.

To characterise the effects of the nanoparticles, the cell surviving fraction (SF) curves were simulated with a linear quadratic law [57]:

$$
S F(D)=e^{-\left(a D+\beta D^{2}\right)}
$$

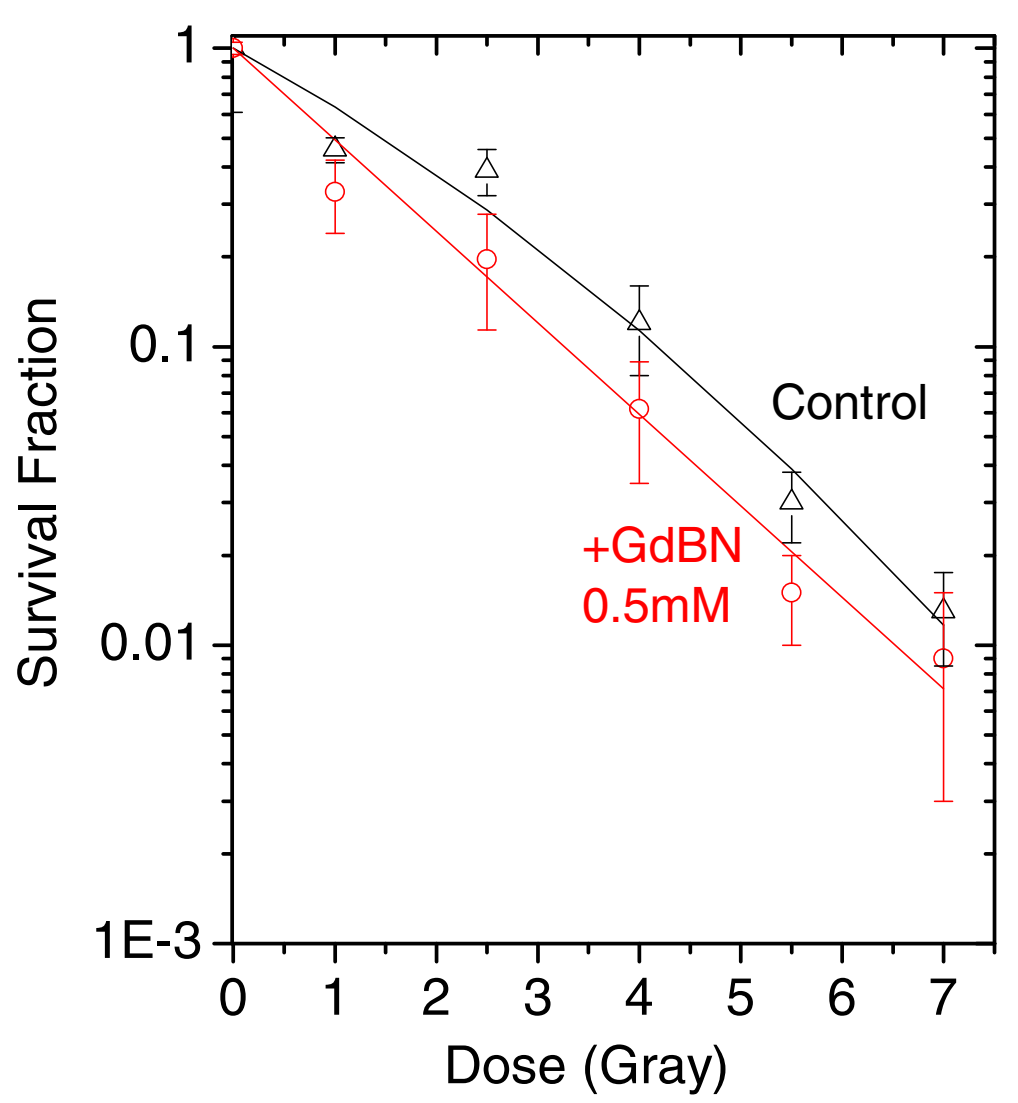

Figure 6 Surviving fraction as function of radiation dose of U87 cells free of GdBN (black) and in the presence of $\mathrm{GdBN}$ (red) irradiated by gamma rays $\left({ }^{60} \mathrm{Co}\right)$. 
Table 2 Coefficients $\alpha$ and $\beta$ calculated for U87 cells irradiated by gamma rays

\begin{tabular}{lcc}
\hline & $\mathbf{a}\left(\mathbf{G y}^{-\mathbf{1}}\right)$ & $\boldsymbol{\beta}\left(\mathbf{G y}^{-\mathbf{2}}\right)$ \\
\hline Control & $0.4 \pm 0.1$ & $0.03 \pm 0.02$ \\
\hline GdBN & $0.71 \pm 0.03$ & 0 \\
\hline
\end{tabular}

where $\mathrm{D}$ is the irradiation dose. The coefficient $\alpha$ corresponds to the contribution of lesions, which are directly lethal for the cell and $\beta$ is attributed to the contribution of additive sub-lethal lesions. The values of $\alpha$ and $\beta$ determined by a fitting procedure are reported in Table 2.

This analysis shows that the presence of GdBN induces an increase of directly lethal lesions $(\alpha)$ and a decrease of sub-lethal lesions $(\beta)$. The enhancement of directly lethal lesions is attributed to the amplification of complex molecular damage as shown elsewhere [23].

The efficiency of GdBN to amplify radiation-induced cell death was characterised by calculating the enhancing factor $(\mathrm{EF})$ at $2 \mathrm{~Gy}$ :

$$
E F=\frac{\left(S F_{\text {control }}^{2 G y}-S F_{G d B N}^{2 G y}\right)}{S F_{\text {control }}^{2 G y}}
$$

The survival fractions at 2 Gy of U87 cells free of NPs $\left(S F_{\text {control }}^{2 G y}\right)$ and loaded with $\operatorname{GdBN}\left(S F_{G d B n}^{2 G y}\right)$ are 0.31 and 0.24 , respectively. The enhancing factor is close to $23 \%$, which characterises the GdBN efficiency when $1.25 \mathrm{MeV}$ gamma rays are used as ionising radiation (see Table 3). These results are complementary to the other studies performed with GdBN and summarised in reference [58].

\section{Conclusions}

The main objective of this work was to probe the efficacy of NPs to amplify radiation effects as a function of their localisation in the cells. We found that GdBN efficiently amplify gamma rays-induced cell killing of U87 cells (by 23\%) even though NPs are located and activated in lysosomes but not in mitochondria. It is the first evidence that the radiosensitisation by NPs may be due to strong perturbations in lysosomes.

This work required the optimisation of an experimental protocol based on the combination of three techniques with the aim to determine unambiguously the localisation of label-free NPs. The synchrotron radiation deep-UV (SR-DUV) microscopy was proposed as a new tool to observe the uptake of label-free NPs that do not absorb in the visible energy range. This elegant technique offers new perspectives in cell microscopy. Conventional TEM was used to determine the uptake mechanism of GdBN. Finally, confocal microscopy was used to investigate the co-localisation of NPs with cell organelles with no artefact of the Cyanine dye in this case. With this set of methods, we demonstrated that GdBN are taken up by U87 cells via endocytosis and start to populate lysosomes 5 hours after incubation but never reach the mitochondria. Thus we

Table 3 Surviving fraction (SF) and enhancing factor (EF) calculated for U87 cells irradiated by gamma rays

\begin{tabular}{lcc}
\hline & SF $^{2}$ Gy & EF \\
\hline Control & 0.31 & \\
\hline GdBN & 0.24 & $22.6 \%$ \\
\hline
\end{tabular}


demonstrated that the amplification of radiation effects by GdBN in U87 cells is related to perturbations induced in the cell lysosomes but not in the respiratory chain system (in the mitochondria). This study is a first step in the understanding of the biological action of GdBN in U87 cells; additional experiments are needed to identify the metabolic functions that are affected by the presence and the activation of NPs in lysosomes.

Finally, the study demonstrates that a combination of experimental protocols-TEM, SR-DUV and confocal microscopy-may be used as a standard method to characterise the action of NPs in different cell lines.

\begin{abstract}
Abbreviations
CEA: Atomic energy center; CHO: Chinese hamster ovary; CPBM: Centre de photonique bio-medical; CTCF: Corrected total cell fluorescence; DMEM: Dulbecco's modified eagle medium; GBM: Glioblastoma multiforme; GdBN: Gadolinium-based nanoparticles; GdBN-Cy5.5: GdBN labelled with cyanine 5.5; HBSS: Hank's balanced salt solution; EELS: Electron energy loss spectroscopy; EF: Enhancing factor; FITC: Fluorescein IsoThioCyanate; ICP: Inductively coupled plasma; LET: Linear energy transfer; NPs: Nanoparticles; SD: Standard deviation; SF: Surviving fraction; SR-DUV: Synchrotron-radiation deep UV; SQ20B: Human head and neck squamous cells carcinoma cell line; TEM: Transmission electron microscopy; U87: Human glioblastoma cell line.
\end{abstract}

\title{
Competing interests
}

The authors of this manuscript have no competing interests as defined by Springer; they do not have any other interests that influence the results and discussion of this paper.

\section{Authors' contributions}

$\mathrm{SL}$, as the head of the group, supervised the project and the experimental strategy. LS, EP and DS performed the localisation experiments by confocal microscopy. LS, EP, PE, SLi, MR and SL carried out the SR-DUV experiments. SM carried out the TEM experiments with the participation of LS, EP, J-LGK, PE and SLi. The irradiation experiments were carried out by EP, PE and SL. OT and FL prepared the gadolinium based nanoparticles. LS, SL and EP wrote the manuscript. All authors read and approved the final manuscript.

\section{Acknowledgement}

The work was supported by the following projects: OPVK CZ.1.07/2.3.00/30.0030, GAČR Center of Excellence P302/12/ G157, COST LD12039 (MŠMT) and EU COST MP1002 Nano-IBCT. We acknowledge Synchrotron SOLEIL access through project \#20130310. We also acknowledge Prof. Erwin Henriquez from Ateneo University (Philippines) for fruitful discussions.

\section{Author details}

'Institut des Sciences Moléculaires d'Orsay (UMR 8214) Bât 351, Université Paris Sud, CNRS, 91405 Orsay Cedex, France. ${ }^{2}$ Institut Curie, centre de recherche, bat 112, Centre Universitaire, 91405 Orsay Cedex, France. ${ }^{3}$ INSERM U759, bat 112, Centre Universitaire, 91405 Orsay Cedex, France. ${ }^{4}$ Synchrotron SOLEIL, BP48 Saint-Aubin, 91192 Gif-sur-Yvette, France. ${ }^{5}$ Institut Lumière Matière, Université Claude Bernard Lyon 1, CNRS, 69622 Villeurbanne cedex, France.

Received: 27 May 2014 Accepted: 9 September 2014

Published online: 10 October 2014

\section{References}

1. Gurney JG, Kadan-Lottick N (2001) Brain and other central nervous system tumors: rates, trends, and epidemiology. Curr Opin Oncol 13:160-166

2. Chithrani DB, Jelveh S, Jalali F, van Prooijen M, Allen C, Bristow RG, Hill RP, Jaffray DA (2010) Gold nanoparticles as radiation sensitizers in cancer therapy. Radiat Res 173:719-728

3. Hainfeld JF, Dilmanian FA, Slatkin DN, Smilowitz HM (2008) Radiotherapy enhancement with gold nanoparticles. J Pharm Pharmacol 60:977-985

4. Hainfeld JF, Slatkin DN, Smilowitz HM (2004) The use of gold nanoparticles to enhance radiotherapy in mice. Phys Med Biol 49:N309-N315

5. Jain S, Coulter JA, Hounsell AR, Butterworth KT, MCMahon SJ, Hyland WB, Muir MF, Dickson GR, Prise KM, Currell FJ, O'Sullivan JM, Hirst DG (2011) Cell-specific radiosensitization by gold nanoparticles at megavoltage radiation energies. Int J Radiat Oncol Biol Phys 79:531-539

6. Chattopadhyay N, Cai Z, Kwon YL, Lechtman E, Pignol J-P, Reilly RM (2013) Molecularly targeted gold nanoparticles enhance the radiation response of breast cancer cells and tumor xenografts to $X$-radiation. Breast Cancer Res Treat 137:81-91

7. Hainfeld JF, Slatkin DN, Focella TM, Smilowitz HM (2006) Gold nanoparticles: a new X-ray contrast agent. Br J Radiol 79:248-253

8. Lim Z-ZI, Li J-EJ, Ng C-T, Yung L-YL, Bay B-H (2011) Gold nanoparticles in cancer therapy. Acta Pharmacol Sin 32:983-990

9. Powell AC, Paciotti GF, Libutti SK (2010) Colloidal gold: a novel nanoparticle for targeted cancer therapeutics. Methods Mol Biol 624:375-384

10. Mieszawska AJ, Mulder WJM, Fayad ZA, Cormode DP (2013) Multifunctional gold nanoparticles for diagnosis and therapy of disease. Mol Pharm 10:831-847 
11. Butterworth KT, McMahon SJ, Currell FJ, Prise KM (2012) Physical basis and biological mechanisms of gold nanoparticle radiosensitization. Nanoscale 4:4830-4838

12. Porcel E, Li S, Usami N, Remita H, Furusawa Y, Kobayashi K, Le Sech C, Lacombe S (2011) Nano-Sensitization Under Gamma Rays and Fast ion Radiation. In: 1st Nano-lbct Conference 2011 - Radiation Damage of Biomolecular Systems: Nanoscale Insights into Ion Beam Cancer Therapy. Journal of Physics: Conference Series, p 373. http://iopscience.iop. org/1742-6596/373/1/012006

13. Le Duc G, Roux S, Tillement O, Perriat P, Billotey C, Mandon C, Mutelet B, Alric C, Janier M, Loui C (2007) Radio-Sensibilisants a base de Nanoparticules Hybrides d'Oxyde de Lanthanide et Methode pour Augmenter I'Efficacite Therapeutique des Radiations par Utilisation de Nanoparticules d'Oxyde de Lanthanides. French Patent 07.58348

14. Sharma P, Brown SC, Walter G, Santra S, Scott E, Ichikawa H, Fukumori Y, Moudgil BM (2007) Gd nanoparticulates: from magnetic resonance imaging to neutron capture therapy. Adv Powder Technol 18:663-698

15. Bridot JL, Faure AC, Laurent S, Riviere C, Billotey C, Hiba B, Janier M, Josserand V, Coll JL, Elst LV, Muller R, Roux S, Perriat P, Tillement O (2007) Hybrid gadolinium oxide nanoparticles: Multimodal contrast agents for in vivo imaging. J Am Chem Soc 129:5076-5084

16. Yim H, Seo S, Na K (2011) MRI contrast agent-based multifunctional materials: diagnosis and therapy. J Nanomater 2011:1-11

17. Lux F, Mignot A, Mowat P, Louis C, Dufort S, Bernhard C, Denat F, Boschetti F, Brunet C, Antoine R, Dugourd P, Laurent S, Vander Elst L, Muller R, Sancey L, Josserand V, Coll JL, Stupar V, Barbier E, Rémy C, Broisat A, Ghezzi C, Le Duc G, Roux S, Perriat P, Tillement O (2011) Ultrasmall rigid particles as multimodal probes for medical applications. Angew Chem Int Ed Engl 50:12299-12303

18. Roux S, Tillement O, Billotey C, Coll J-L, Le Duc G, Marquette CA, Perriat P (2010) Multifunctional nanoparticles: from the detection of biomolecules to the therapy. Int J Nanotechnol 7:781-801

19. Bianchi A, Dufort S, Lux F, Courtois A, Tillement O, Coll J-L, Crémillieux Y (2013) Quantitative biodistribution and pharmacokinetics of multimodal gadolinium-based nanoparticles for lungs using ultrashort TE MRI. MAGMA 27(4):303-316. doi:10.1007/s10334-013-0412-5

20. Mignot A, Truillet C, Lux F, Sancey L, Louis C, Denat F, Boschetti F, Bocher L, Gloter A, Stephan O, Antoine R, Dugourd P, Luneau D, Novitchi G, Figueiredo LC, de Morais PC, Bonneviot L, Albela B, Ribot F, Van Lokeren L, Déchamps-Olivier I, Chuburu F, Lemercier G, Villiers C, Marche PN, Le Duc G, Roux S, Tillement O, Perriat P (2013) A top-down synthesis route to ultrasmall multifunctional Gd-based silica nanoparticles for theranostic applications. Chem Eur J 19:6122-6136

21. Le Duc G, Miladi I, Alric C, Mowat P, BrÃauer-Krisch E, Bouchet A, Khalil E, Billotey C, Janier M, Lux F, Epicier T, Perriat $P$, Roux S, Tillement O (2011) Toward an image-guided microbeam radiation therapy using gadoliniumbased nanoparticles. ACS Nano 5:9566-9574

22. Mowat P, Mignot A, Rima W, Lux F, Tillement O, Roulin C, Dutreix M, Bechet D, Huger S, Humbert L, Barberi-Heyob M, Aloy MT, Armandy E, Rodriguez-Lafrasse C, Le Duc G, Roux S, Perriat P (2011) In vitro radiosensitizing effects of ultrasmall gadolinium based particles on tumour cells. J Nanosci Nanotechnol 11(9):7833-7839

23. Porcel E, Tillement O, Lux F, P M, Usami N, Kobayashi K, Furusawa Y, Le Sech C, Li S, Lacombe S (2014) Gadolinium-based nanoparticles to improve the hadrontherapy performances. Nanomedicine, in press

24. Krpetic Z, Nativo P, See V, Prior IA, Brust M, Volk M (2010) Inflicting controlled nonthermal damage to subcellular structures by laser-activated gold nanoparticles. Nano Lett 10:4549-4554

25. Porcel E, Liehn S, Remita H, Usami N, Kobayashi K, Furusawa Y, Le Sech C, Lacombe S (2010) Platinum nanoparticles: a promising material for future cancer therapy? Nanotechnology 21:7

26. Chang M-Y, Shiau A-L, Chen Y-H, Chang C-J, Chen HHW, Wu C-L (2008) Increased apoptotic potential and doseenhancing effect of gold nanoparticles in combination with single-dose clinical electron beams on tumor-bearing mice. Cancer Sci 99:1479-1484

27. Kong T, Zeng J, Wang X, Yang X, Yang J, McQuarrie S, McEwan A, Roa W, Chen J, Xing JZ (2008) Enhancement of radiation cytotoxicity in breast-cancer cells by localized attachment of gold nanoparticles. Small 4:1537-1543

28. Usami N, Furusawa Y, Kobayashi K, Lacombe S, Reynaud-Angelin A, Sage E, Wu T-D, Croisy A, Guerquin-Kern JL, Le Sech C (2008) Mammalian cells loaded with platinum-containing molecules are sensitized to fast atomic ions. Int J Radiat Biol 84:603-611

29. Zhang X, Xing JZ, Chen J, Ko L, Amanie J, Gulavita S, Pervez N, Yee D, Moore R, Roa W (2008) Enhanced radiation sensitivity in prostate cancer by gold-nanoparticles. Clin Invest Med 31:E160-E167

30. Rima W, Sancey L, Aloy M-T, Armandy E, Alcantara GB, Epicier T, Malchere A, Joly-Pottuz L, Mowat P, Lux F, Tillement O, Burdin B, Rivoire A, Boulé C, Anselme-Bertrand I, Pourchez J, Cottier M, Roux S, Rodriguez-Lafrasse C, Perriat P (2013) Internalization pathways into cancer cells of gadolinium-based radiosensitizing nanoparticles. Biomaterials 34:181-195

31. Glauert AM, Lewis PR (1998) Biological Specimen Preparation for Transmission Electron Microscopy. In: Audrey M, Glauert E (eds) Practical Methods in Electron Microscopy. Volume 17. Portland Press, London, p 326

32. Hoetzer B, Medintz IL, Hildebrandt N (2012) Fluorescence in nanobiotechnology: sophisticated fluorophores for novel applications. Small 8:2297-2326

33. Jiang J, Oberdorster G, Biswas P (2009) Characterization of size, surface charge, and agglomeration state of nanoparticle dispersions for toxicological studies. J Nanoparticle Res 11:77-89

34. Pietzonka P, Rothen-Rutishauser B, Langguth P, Wunderli-Allenspach H, Walter E, Merkle HP (2002) Transfer of lipophilic markers from PLGA and polystyrene nanoparticles to Caco-2 monolayers mimics particle uptake. Pharm Res 19:595-601

35. Salvati A, Aberg C, dos Santos T, Varela J, Pinto P, Lynch I, Dawson KA (2011) Experimental and theoretical comparison of intracellular import of polymeric nanoparticles and small molecules: toward models of uptake kinetics. Nanomedicine 7:818-826

36. Kascakova S, Maigre L, Chevalier J, Refregiers M, Pages J-M (2012) Antibiotic transport in resistant bacteria: synchrotron UV fluorescence microscopy to determine antibiotic accumulation with single cell resolution. PLoS One 7(6):e38624. doi:10.1371/journal.pone.0038624 
37. Fizet J, Riviere C, Bridot JL, Charvet N, Louis C, Billotey C, Raccurt M, Morel G, Roux S, Perriat P, Tillement O (2009) Multi-luminescent hybrid gadolinium oxide nanoparticles as potential cell labeling. J Nanosci Nanotechnol 9:5717-5725

38. Louis C, Bazzi R, Marquette CA, Bridot JL, Roux S, Ledoux G, Mercier B, Blum L, Perriat P, Tillement O (2005) Nanosized hybrid particles with double luminescence for biological labeling. Chem Mater 17:1673-1682

39. Wagnieres GA, Star WM, Wilson BC (1998) In vivo fluorescence spectroscopy and imaging for oncological applications. Photochem Photobiol 68:603-632

40. Huang C-Y, Ger T-R, Wei Z-H, Lai M-F (2014) Compare analysis for the nanotoxicity effects of different amounts of endocytic iron oxide nanoparticles at single cell level. PLoS One 9(5):e96550. doi:10.1371/journal.pone.0096550

41. Huotari J, Helenius A (2011) Endosome maturation. Embo J 30:3481-3500

42. Kerr MC, Teasdale RD (2009) Defining macropinocytosis. Traffic 10:364-371

43. Xu P, Gullotti E, Tong L, Highley CB, Errabelli DR, Hasan T, Cheng J-X, Kohane DS, Yeo Y (2009) Intracellular drug delivery by poly(lactic-co-glycolic acid) nanoparticles, revisited. Mol Pharm 6:190-201

44. Conner SD, Schmid SL (2003) Regulated portals of entry into the cell. Nature 422:37-44

45. Shikata F, Tokumitsu H, Ichikawa H, Fukumori Y (2002) In vitro cellular accumulation of gadolinium incorporated into chitosan nanoparticles designed for neutron-capture therapy of cancer. Eur J Pharm Biopharm 53:57-63

46. Tseng C-L, Shih IL, Stobinski L, Lin F-H (2010) Gadolinium hexanedione nanoparticles for stem cell labeling and tracking via magnetic resonance imaging. Biomaterials 31:5427-5435

47. Liu K-K, Wang C-C, Cheng C-L, Chao J-I (2009) Endocytic carboxylated nanodiamond for the labeling and tracking of cell division and differentiation in cancer and stem cells. Biomaterials 30:4249-4259

48. Thurn KT, Arora H, Paunesku T, Wu A, Brown EMB, Doty C, Kremer J, Woloschak G (2011) Endocytosis of titanium dioxide nanoparticles in prostate cancer PC-3 M cells. Nanomedicine 7:123-130

49. Bolte S, Cordelieres FP (2006) A guided tour into subcellular colocalization analysis in light microscopy. J Microsc 224:213-232

50. Manders EMM, Stap J, Brakenhoff GJ, Vandriel R, Aten JA (1992) Dynamics of 3-dimensional replication patterns during the S-phase, analyzed by double labeling of DNA and confocal microscopy. J Cell Sci 103:857-862

51. Zinchuk V, Zinchuk O (2008) Quantitative colocalization analysis of confocal fluorescence microscopy images. Curr Protoc Cell Biol Chapter 4:Unit 4.19-Unit 14.19

52. Neun BW, Stern ST (2011) Monitoring lysosomal activity in nanoparticle-treated cells. Methods Mol Biol 697:207-212

53. Bexiga MG, Varela JA, Wang F, Fenaroli F, Salvati A, Lynch I, Simpson JC, Dawson KA (2011) Cationic nanoparticles induce caspase 3-, 7- and 9-mediated cytotoxicity in a human astrocytoma cell line. Nanotoxicology 5:557-567

54. Lesniak A, Campbell A, Monopoli MP, Lynch I, Salvati A, Dawson KA (2010) Serum heat inactivation affects protein corona composition and nanoparticle uptake. Biomaterials 31:9511-9518

55. Shapero K, Fenaroli F, Lynch I, Cottell DC, Salvati A, Dawson KA (2011) Time and space resolved uptake study of silica nanoparticles by human cells. Mol Biosyst 7:371-378

56. Shi H, He X, Yuan Y, Wang K, Liu D (2010) Nanoparticle-based biocompatible and long-life marker for lysosome labeling and tracking. Anal Chem 82:2213-2220

57. Dutreix J, Wanbersie A, Tubiana M (1990) Introduction to Radiobiology. Taylor \& Francis, London, UK

58. Sancey L, Lux F, Kotb S, Roux S, Dufort S, Bianchi A, Cremilleux Y, Fries P, Coll JL, Rodriguez-Lafrasse C, Janier M, Dutreix M, Barberi-Heyob M, Boschetti F, Denat F, Louis C, Porcel E, Lacombe S, Le Duc G, Deutsch E, Perfettini JL, Detappe A, Verry C, Berbecco R, Butterworth K, McMahon S, Prise K, Perriat P, Tillement O (2004) The use of theranostic gadolinium-based nanoprobes to improve radiotherapy efficacy. Br J Radiol, in press

doi:10.1186/s12645-014-0006-6

Cite this article as: Štefančíková et al:: Cell localisation of gadolinium-based nanoparticles and related radiosensitising efficacy in glioblastoma cells. Cancer Nanotechnology 2014 5:6.

\section{Submit your manuscript to a SpringerOpen ${ }^{\circ}$ journal and benefit from:}

- Convenient online submission

Rigorous peer review

- Immediate publication on acceptance

- Open access: articles freely available online

- High visibility within the field

- Retaining the copyright to your article

Submit your next manuscript at $\gg$ springeropen.com 